\title{
Build and implement of Independent college teachers team construction Auxiliary decision system Based on framework of said
}

\author{
Qing-RuSui ${ }^{1, a}$
}

1School of Changchun University Of Science And Technology, Changchun 130600, China.

a 404409709 @qq.com

Keywords: Independent college, Teachers troop, Assistant decision.

\begin{abstract}
The independent college wants long-term development will have areasonable structure of teaching staff, because the independent college teaching situation has its unique characteristics. So in independent college teachers, on the basis of the basic situation of the existing framework is used to describe the teachers, and building a supporting system of independent college teachers team construction. This article mainly elaborated system's main function, the realization of the mathematical model and mathematical model of the content.
\end{abstract}

\section{Introduction}

Independent college is organized by the ordinary colleges and universities and social forces mainly for undergraduate education of higher education institutions, along with our country higher education scale expansion and the reform of the education system of new things [1].In the fierce market competition, the competition between colleges and universities has become competition for teachers, students and independent college to be in the invincible position in the competition, must have a noble ethics, business skilled teachers [2]. Teachers team construction of the auxiliary decision system of the students and the teachers of integrated analysis and assisted in Independent Colleges Teachers "rational distribution, training, employment etc. provide a reference basis.

\section{Basic structure of the frame}

Framework is a data structure of a kind of scene structure is composed of a frame name and some slots (slot), each slot has some value, the slot values for logic, digital, procedures, conditions, default, or is a sub framework. Trough value contains information on how to use frame information, might happen next, is expected to achieve the information on how to do, and so on.

General format of frame:

FRAMEWORK: <framework name>

$<$ slot $1>$

$<$ face $11>$ :value

$\cdots$

$<$ face $1 \mathrm{n}>$ :value

$<$ slot 2>

$<$ face $21>$ :value

$<$ face 2 n>:value
Such as:

framework: < university teachers>

Category: $<$ teacher $>$

Education degree:(Bachelor, master, doctor)

Professional: $<$ disciplines $>$

Job title:(ta, lecturer, Associate professor,

professor)

Foreign language:

Scope:(English, French, German,...)

Default: English

Level: (excellent, good, medium)

Default: good 


\section{System main functions}

The system to fully use network resources, to existing teachers (including its own teachers and foreign teachers employed) unified management and allocation, to reduce the waste of existing resources, so as to establish a healthy and rational faculty.

Through the above analysis, the system should have the following functions:

The teacher information management functions.Part of the teachers' information management mainly includes the teacher of some personal information such as: name, age, where the Department, existing title, taught the course name etc., these basic data results presented can pave the way for part of the auxiliary decision-making.

The teacher's basic information can be by human resources departments of the relevant personnel responsible for entry or modify, can also be carried out through the branch secretary of teaching, but also by the teachers themselves to complete the maintenance of personal information.

The teachers troop construction of the auxiliary decision-making functions. The use of this module can help the independent college to recruit new teachers and help the school leaders to choose the teachers. With the teachers of information entry, modify, making the system tends to be perfect, we can according to the existing teacher information, analysis of the target year plans to recruit teachers, includingNew hires should degree in age, job title and even academic status, This is advantageous to the independent colleges and universities to build a reasonable structure of teaching staff.

The function of the independent college teachers' construction auxiliary system design process is shown in Fig. 1.

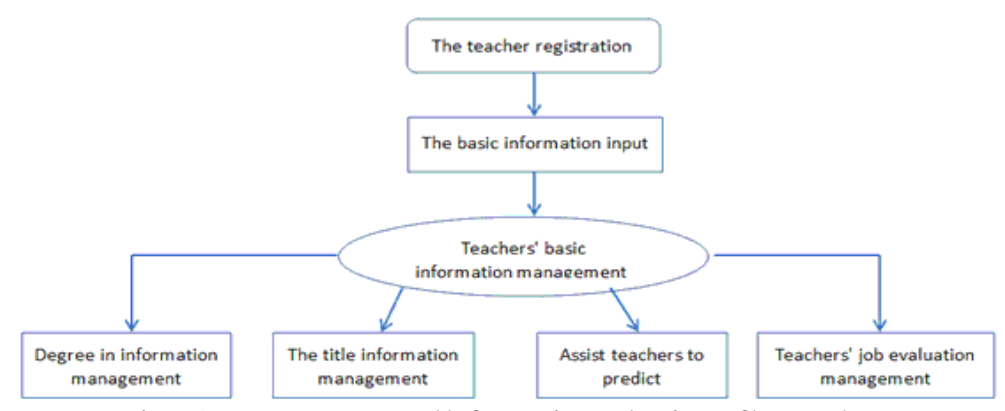

Fig. 1system overall function design flow chart

\section{The establishment of the mathematical model.}

Mathematical model is adopted in the design of the hierarchy system model,its meaning is according to the known condition and the current structure to predict the required data, in order to find a response to the hierarchy of the ideal.In the construction of teachers team auxiliary system of teachers' basic information, including: employee's personal information, every year plans to hire teachers and students of each grade teaching of the courses taught by teachers, these data are stored in the database of this system. To complete the data acquisition and filtering, must use the method of mathematical statistics to calculate the past years the composition proportion.

School administrators in the auxiliary decision-making process, already know data including target informationthat according to the development of the independent collegeset by the planning and construction of teachers' team planning teaching staff to achieve the overall goal of. Including the teaching staff structure and scale, analysis, and find out the middle years of the change of personnel in accordance with the basic equation to realize the goal of measuring the hierarchy. This system auxiliary functions including teachers' supplementary measure and participating personnel selection calculation of two parts.In teachers supplement section, according to the corresponding degree (bachelor, master and doctor) structure measure should be added on the number of teachers in each of the target years ago. According to the requirement of the target in scale and degree structure and the status of the current personnel structure, measure demand should fill the number of 
teachers' appointment and its corresponding number of degree structure; In the participating researchers chose to measure teachers, must according to the different specialty, different directions on the same course easy to master degree of different requirements to measure to what extent teachers to teach.

Suppose system from low to high divided into $\mathrm{m}$ level, Level is expressed as $\mathrm{I}=1,2,3 \ldots \mathrm{M}$, the parameter $t$ means value year.

- Researchers said rank vector (by number) :

$$
\left.n(t)=\left(n_{1}(t)\right), \quad n_{2}(t), \cdots \cdots n_{m}(t)\right)
$$

In which $n_{i}(t)$ isthe number of people for the first $t$ yearsbelong to grade $i$,

Set the first $\mathrm{t}$ in the total number of $\mathrm{N}(\mathrm{t})$ of the whole system, there are: $N(t)=\sum_{i=1}^{m} n_{i}(t)$

Researchers said rank vector (proportional) :

$a(t)=\left(a_{1}(t), \quad a_{2}(t), \cdots \cdots \cdot a_{m}(t)\right)$

In Which $a_{i}(t)$ is the first $t$ years throughout the system belongs to the number of level $i$, $\mathrm{a}_{\mathrm{i}}(\mathrm{t})=\mathrm{n}_{\mathrm{i}}(\mathrm{t}) / \mathrm{N}(\mathrm{t})$,

The vector form is: $n(t)=\left(n_{1}(t), n_{2}(t), \cdots \cdots n_{m}(t)\right)$

$$
=N(t)\left(a_{1}(t), a_{2}(t), \cdots \cdots a_{m}(t)\right)
$$

So $\mathrm{a}_{\mathrm{i}}(\mathrm{t}) \geqslant 0$, and $\sum_{i=1}^{m} a_{i}(t)=1$

- The introduction of personnel rank vector (by number) :

$r(t)=\left(r_{l}(t), \quad r_{2}(t), \cdots \cdots r_{m}(t)\right)$

In which $r_{i}(t)$ is the first $t$ years number of introduction of grade $i$, Assuming that the total of the

whole system the first $\mathrm{t}$ years of number is $\mathrm{R}(\mathrm{t})$ there are:

$$
R(t)=\sum_{i=1}^{m} r_{i}(t)
$$

- The introduction of personnel rank vector (proportional) :

$\mathrm{S}(\mathrm{t})=\left(\mathrm{S}_{1}(\mathrm{t}), \quad \mathrm{S}_{2}(\mathrm{t}), \cdots \cdots \mathrm{S}_{\mathrm{m}}(\mathrm{t})\right)$

In which $S_{i}(t)$ is the first $t$ years the introduction of grade i number of personnel in the total of the proportion of introduction. The first introduction of level $i$, the number of $t$ years as follows: $r_{i}(t)=R(t) S_{i}(t)$,

Introduction of personnel rank vector can be represented as:

$r(t)=\left(r_{i}(t), \quad r_{2}(t), \cdots \cdots r_{m}(t)=R(t)\left(S_{1}(t), \quad S_{2}(t), \cdots \cdots S_{m}(t)\right)\right.$ 。

$\cdot(\mathrm{t}+1)$ equation of the total number of years :

In $(t+1)$, the total number of the system include: The $t$ years of the original number of teachers with the $(t+1)$ in the new hiring teachers .Because of using independent college is the employment contract signed by the employee are usually for five years or ten years, there is no special circumstances college was not cut out of the staff, with the independent college is gradually tending to improve various system. The number of employees to leave is reducing year by year.Based on the above reasons in this system the number of employee turnover is negligible.So there are:

$\mathrm{N}(\mathrm{t}+1)=\mathrm{N}(\mathrm{t})+\mathrm{R}(\mathrm{t})$

- The choice of the instructor

According to the evaluation results of teachers students and schools, as well as a professional master degree on a course for different to choose suitable teacher to teach .The teachers' degree is divided into three levels: 5points on behalf of excellent, 3points on behalf of good,1 minute for medium. The integrity of the excellent teachers accounted for $15 \%$ of the total number of teachers, school of good teachers account for $70 \%$ of the total number of college teachers, secondary teachers 
account for $15 \%$ of the total number of college.So with the following formula:

The number of excellent $=\mathrm{N}(\mathrm{t}+1) \times 15 \%$

The number of good $=\mathrm{N}(\mathrm{t}+1) \times 70 \%$

The number of medium $=\mathrm{N}(\mathrm{t}+1) \times 15 \%$

Through the above equation, it can predict target in supplementary information of teachers and choose a certain professional course teacher, and forecast results, achieve the purpose of the forecast of the system.

Teaching is the lifeline of universities, the outstanding of teachers is not only the quality of teaching in colleges and universities favorable safeguard, also is the core element of the colleges and universities to improve their competitiveness.

Said in this paper, based on the framework of the system of the construction of the auxiliary teaching staff as an aid to teaching management unit of information storage, extraction and analysis of teachers, has effective function to predict the change trend of teachers, to build a meet the demand of teaching and scientific research in colleges and universities demand of teachers group.

\section{References}

[1] Hong-LianYu,Hong-yueLi, independent college teachers team construction of problem analysis and countermeasures. China collective economy. 2007

[2] Xiao-Ming Tu, Jian-Ming Tu. Explore our country independent institute of standardization development. Development and evaluation of higher education. 2009

[3] Li-jieHe, introduction to "mathematical model". Jilin education. 2010 